\title{
Hiperjornalismo: uma visada sobre fake news a partir da autoridade jornalística ${ }^{1}$
}

\section{Hyperjournalism: a look on fake news from the journalistic authority perspective}

\section{Marco Antonio Roxo}

Instituto de Arte e Comunicação Social, Programa de Pós-Graduação em Comunicação, Universidade Federal Fluminense, Niterói, RJ, Brasil ORCID: 0000-0001-5398-622X

<marcos-roxo@uol.com.br>

\author{
Seane Melo \\ Instituto de Arte e Comunicação Social, Programa de \\ Pós-Graduação em Comunicação, Universidade Federal \\ Fluminense, Niterói, Brasil \\ ORCID: 0000-0001-9513-3946 \\ <seanemelo@gmail.com>
}

\section{Como citar este artigo (How to cite this article):}

ROXO, Marco Antonio; MELO, Seane. Hiperjornalismo: uma visada sobre fake news a partir da autoridade jornalística. Revista Famecos, Porto Alegre, v. 25, n. 3, p. 1-19, setembro, outubro, novembro e dezembro de 2018: ID30572. DOl: http://dx.doi.org/10.15448/1980-3729.2018.3.30572.

\section{RESUMO}

Neste artigo, procuramos contribuir para o debate sobre fake news a partir do entendimento de que estaríamos vivendo uma era de "hiperjornalismo". Com essa proposta, deslocamos o ponto de vista das ferramentas ou soluções disponíveis para evitar a propagação de notícias falsas em sites de redes sociais para uma reflexão sobre as condições de emergência desse fenômeno. Nossa hipótese é de que as notícias falsas também são consequência de um movimento a partir do qual o campo jornalístico consegue impor suas regras internas para outros campos de produção. Com base nisso, questionamos se é em torno das oposições entre verdade e mentira, entre investigação jornalística ou falta dela, que poderemos avançar nessa discussão e sugerimos que a discussão da veracidade não pode ser separada da discussão da autoridade e do pacto de credibilidade entre meios de comunicação e cidadãos.

\begin{abstract}
In this paper, we seek to contribute to the debate on fake news through the perpective of a hyperjournalism era. With this proposal, we moved the point of view from the tools or solutions available to avoid the spread of false news on social networking sites for a reflection on the emergency conditions of this phenomenon. Our hypothesis is that false news are also the consequence of a movement from which the journalistic field manages to impose its internal rules on other fields of production. Based on this, we question whether it is around the opposition between truth and lie, between journalistic investigation or the lack of it, that we can move this debate forward, and suggest that such discussion should not be separated from the discussion of authority and from the credibility pact between media and citizens.
\end{abstract}

Keywords: Fake news. Hyperjournalism. Journalistic authority.

Palavras-chave: Fake news. Hiperjornalismo. Autoridade jornalística.

\section{Introdução}

Em uma busca preliminar pelas palavras fake news no portal da Folha de $S$. Paulo é possível constatar que, só de 01 de janeiro a 26 de abril de 2018, o termo

1 Uma versão preliminar desse artigo foi apresentada no $40^{\circ}$ Congresso Brasileiro de Ciências da Comunicação. 
apareceu 257 vezes nas reportagens e colunas do jornal. Se este número por si só não servir como expressão da crescente relevância que o "fenômeno" vem adquirindo, poderíamos acrescentar que ele representa $50 \%$ das ocorrências da expressão no site em qualquer período². Apontado como um fenômeno que emergiu em 2016 durante as eleições presidenciais nos Estados Unidos, fake news com frequência aparece como sinônimo de pós-verdade, adjetivo "relativo a ou denotando circunstâncias em que fatos objetivos são menos influentes na formação da opinião pública que os apelos à emoção e às crenças pessoais" ${ }^{\prime \prime}$ A expressão também foi incorporada aos debates de jornalismo (Zuckerman, 2017; Boyd, 2017; Caplan, 2017), e influenciou diretamente iniciativas como o Google News Lab4 - que estabeleceu "Confiança e Verificação" como um de seus quatro focos de atuação - e recentes atualizações do site de rede social Facebook ${ }^{5}$.

A bibliografia consultada durante a confecção desse artigo está em grande medida direcionada para o desenvolvimento de ferramentas e soluções que evitem a propagação destes conteúdos e seus impactos nos processos políticos. De nossa parte, pretendemos contribuir para a discussão por outro caminho, isto é, pela reflexão sobre as condições de emergência do fenômeno. Para isso, partimos de uma análise de Bolin (2014) sobre a autonomia do campo jornalístico na televisão sueca. Autonomia entendida no sentido de Bourdieu (1996, p. 249), como capacidade de subordinar o princípio de hierarquização externa (isto é, o princípio em vigor "nas regiões temporalmente dominantes do campo do poder" e no campo econômico) ao princípio de hierarquização interna (a consagração específica e independente).

Segundo Bolin, quando tomamos o jornalismo como um subcampo do campo de produção cultural, que consegue impor sua lógica e suas regras - principalmente, a partir do estabelecimento da entrevista como prática profissional; da ocupação, por jornalistas, de posições externas ao campo; e da institucionalização da formação jornalística - podemos entender a imbricação entre jornalismo e entretenimento para além da visão do infotainment (Brants, 1998) ${ }^{6}$, que enfatiza sobretudo a dependência econômica do campo jornalístico em detrimento da autonomia necessária para a prática profissional séria e comprometidacomafunçãodeinformarocidadão paraoexercício da democracia. Como veremos, outro caminho é o da observação dos impactos culturais que

2 No momento da produção desse artigo, a ocorrência total de "fake news" no site da Folha de S. Paulo era de 508 vezes.

3 No original: "[...] relating to or denoting circumstances in which objective facts are less influential in shaping public opinion than appeals to emotion and personal belief" (POST-TRUTH, 2017)

4 Disponível em: https://newslab.withgoogle.com/about. Acesso em: 15 Jul. 2017.

5 Cf. MOSSERI (2017).

6 Confira a discussão desse conceito na bibliografia brasileira em Gomes (2011). 
os princípios de hierarquização interna, como padrões de como se fazer bom jornalismo, exercem em outros campos ou subcampos de produção cultural.

Ainda que o autor esteja analisando pontualmente o contexto televisivo sueco, suas reflexões são importantes para pensar que a relação entre jornalismo e entretenimento, amplamente denunciadas como um esvaziamento ou contaminação do primeiro pelo segundo, também podem ser reflexos de disputas nas quais o jornalismo conseguiu impor, culturalmente, a sua lógica e expandir a sua área de atuação. Assim como na TV pode-se observar métodos e linguagens inicialmente desenvolvidos no âmbito da prática jornalística figurarem nos mais diversos formatos televisivos, do talk show ao reality show; as pesquisas que têm demonstrado o aumento do consumo de notícias partindo de sites de redes sociais (no Brasil, por exemplo, $66 \%$ do consumo de notícias digitais acontece assim) podem ser um indicativo não apenas do crescimento desses sites, mas, também, da importância do jornalismo para engajar usuários na produção e circulação de informações. O crescimento da presença do jornalismo na televisão ou nas plataformas de redes sociais e a sua diferenciação em várias subformas distintas, então, representaria uma era em que, em vez de "morte", haveria um alargamento da prática, representado pelo termo "hiperjornalismo". Cabe notar, sobre a utilização do termo "hiperjornalismo", que não se trata de um conceito operacional deste trabalho, antes trata-se de um termo contextual, isto é, uma expressão que marca uma leitura diferente dos atravessamentos entre jornalismo e outras áreas, leitura na qual se enfatiza os impactos culturais do jornalismo em outros campos de produção.

Após justificarmos a abordagem das fake news dentro da lógica de uma era do hiperjornalismo, retomamos, enfim, a discussão de Sodré (2011) sobre o pacto de credibilidade do jornalismo e indagamos quanto às consequências dessa influência do jornalismo sobre outros subcampos de produção cultural para a autoridade jornalística. De acordo com Zelizer (1992, p. 11), a autoridade jornalística diz respeito à "capacidade dos jornalistas de se afirmarem como porta-vozes legitimados e confiáveis dos eventos da 'vida real'", e, como argumenta a autora, essa capacidade não está institucionalizada como parte da profissão. Antes, a autoridade jornalística é fruto da capacidade dos jornalistas de utilizar os códigos de conhecimento coletivo. Uma vez que o jornalismo apresenta a característica de não ser uma profissão tão formalizada, que funcionaria como uma comunidade interpretativa ${ }^{7}$, a utilização de métodos e

7 É importante frisar que a noção de autoridade envolve a formação de uma comunidade de "profissionais". Muito embora Zelizer pense os jornalistas como comunidade de intérpretes, já que os padrões de o que é notícia entre os jornalistas norte-americanos são relativamente compartilhados, a autoridade implica também na forma como os jornalistas defendem suas fronteiras de amadores e 
linguagens jornalísticas em outros gêneros de produção cultural desvinculados do compromisso com a verdade e com objetivos distintos do jornalismo não dificultaria a afirmação de sua autoridade?

Em síntese, argumentamos que o fenômeno de notícias falsas emerge a partir do ganho de autonomia do campo jornalístico sobre outros campos de produção cultural - autonomia que seria representada não em termos econômicos, mas pela influência cultural do texto e de técnicas do jornalismo em outras produções - e que, em virtude dessa emergência, juntamente com mudanças tecnológicas que reduzem a assimetria entre jornalistas e sua audiência, um ponto central para o estudo das fake news seria o das estratégias de reafirmação da autoridade jornalística.

\section{Um fenômeno em definição}

Em artigo publicado no site da transmissora alemã Deutsche Welle, Zuckerman (2017) disserta sobre os diversos sentidos da expressão fake news. Ainda que, à primeira vista, a expressão aparente ser autoexplicativa, referindose simplesmente a "notícias falsas", a complexidade do cenário contemporâneo, seja político ou midiático, coloca em cena outras compreensões possíveis. 0 autor aponta três delas: 1) no primeiro sentido, fake news são entendidas como fatos reais que não mereciam tanta atenção quanto receberam; 2) a expressão também aparece como sinônimo de propaganda, especialmente de propaganda política: "[...]discurso utilizado como arma que mistura discurso verdadeiro, enganoso e falso, e é projetado explicitamente para fortalecer um lado e enfraquecer o outro"(Zuckerman, 2017,s/p) ; 3) por fim, fake news também pode ser uma forma de designar o que o autor chama de disinformatzya, isto é, falsas notícias que não possuem a intenção de convencer alguém de algo, sim, de poluir os meios de comunicação e gerar suspeitas em relação a confiabilidade das empresas de comunicação em geral.

Alcott e Gentzkow (2017, p. 213) optam por uma definição instrumental de fake news para selecionar seu corpus de análise que enfatiza sua intencionalidade, a possibilidade de verificação e seus efeitos. Para eles, a expressão define notícias intencionalmente falsas, cuja falsidade pode ser comprovada, destinadas a

diletantes. Daí a questão da formalização das práticas via formação acadêmica, que implica na existência de uma "ideologia profissional" na qual os jornalistas tentam defender suas fronteiras.

8 No original: "[...] weaponized speech that mixes truthful, deceptive and false speech, and is designed explicitly to strengthen one side and weaken the other" (Zuckerman, 2017, s/p). 
enganar o leitor ${ }^{9}$. Os autores também tomam o cuidado de separar as notícias que cumprem esses requisitos de seus "primos próximos".

\begin{abstract}
Nossa definição exclui vários primos próximos das fake news: 1) erros de comunicação não intencionais, como uma reportagem recente que informou incorretamente de que Donald Trump havia removido um busto de Martin Luther King Jr. do Salão Oval da Casa Branca; 2) rumores que não se originam de uma determinada notícia; 3 ) teorias da conspiração (estas são, por definição, difíceis de verificar como verdadeiras ou falsas, e são tipicamente originadas por pessoas que acreditam que sejam verdadeiras); 4) sátiras improváveis de serem mal interpretadas como notícias factuais; 5 ) declarações falsas de políticos; e 6) relatórios que são tendenciosos ou enganosos, mas não totalmente falsos (na linguagem de Gentzkow, Shapiro e Stone 2016, notícias falsas são "distorção", não "filtragem") (Alcott e Gentzkow, 2017, p. 214). ${ }^{10}$
\end{abstract}

Nesta citação, observamos a diversidade de formas com que notícias ou, para ser preciso, textos que imitam o estilo jornalístico - podem deixar de atender aos critérios profissionais do jornalismo na sua relação com a verdade, no sentido estrito de correspondência com os fatos.

Selecionamos as contribuições dos pesquisadores acima mencionados com o objetivo de sublinhar exatamente a diversidade discursiva em torno da definição de fake news. Por ora, acreditamos que não é necessário optar por qualquer uma das definições, porém, é imprescindível ressaltar um fato que perpassa todo esse debate: a referência aos sites de redes sociais. Assim, ainda que possamos recuperar diversos exemplos de mentiras na história do jornalismo, não podemos confundir qualquer notícia falsa com as que estão no centro dos debates desde a última eleição presidencial nos Estados Unidos. De forma que a diminuição das barreiras para entrada na indústria midiática proporcionada pela internet e o crescimento no uso de sites de redes sociais (Alcott e Gentzkow, 2017), notadamente Facebook, devem ser vistos como

9 No original: "[N]ews articles that are intentionally and verifiably false, and could mislead readers" (Alcott e Gentzkow, 2017, p. 213).

10 No original: "Our definition rules out several close cousins of fake news: 1) unintentional reporting mistakes, such as a recent incorrect report that Donald Trump had removed a bust of Martin Luther King Jr. from the Oval Office in the White House; 2 ) rumors that do not originate from a particular news article; 3) conspiracy theories (these are, by definition, difficult to verify as true or false, and they are typically originated by people who believe them to be true); 4) satire that is unlikely to be misconstrued as factual; 5) false statements by politicians; and 6) reports that are slanted or misleading but not outright false (in the language of Gentzkow, Shapiro, and Stone 2016, fake news is "distortion," not "filtering")" (Alcott e Gentzkow, 2017, p. 214). 
condições de possibilidade para que se possa falar de notícias falsas como um fenômeno cuja relevância é crescente.

\section{A influência cultural do jornalismo}

Em artigo publicado em 2014, que estuda a imbricação entre jornalismo e entretenimento na televisão sueca, Bolin utiliza Bourdieu como referencial teórico para demonstrar como as relações de poder no campo jornalístico são mais complexas do que fazem parecer outros estudos, utilizando o mesmo referencial, que focaram excessivamente nos constrangimentos econômicos na prática jornalística (Bourdieu, 1997; Champagne, 2005).

Opondo-se ao que chama de tese da comercialização, - segundo a qual mudanças no rádio e na televisão seriam consequência das demandas do mercado que privilegiam o entretenimento em todas as áreas de cobertura, incluindo o debate político - Bolin defende que o campo jornalístico enquanto subcampo de produção cultural se tornou mais autônomo, no sentido de ter autonomia para determinar as regras do jogo ou, como dissemos anteriormente, impor seus princípios de hierarquização interna, que estão associados com o fazer jornalístico de qualidade.

Para chegar a essa conclusão, o autor analisa três mudanças no campo jornalístico sueco: 1) a emergência da entrevista como o principal método jornalístico nos anos 1970, responsável por alterar o status do jornalista de alguém que retransmitia fatos que chegavam à redação via telegramas e telefonemas para alguém que realmente produzia notícias a partir do seu trabalho ativo; 2) Mudanças nas políticas de recrutamento no rádio sueco nos anos 1950. Até 1945, o princípio de recrutamento da Swedish Radio (SR) foi guiado pelo grau de escolaridade acadêmica. Com o aparecimento da TV e a expansão da companhia, nos anos 1950, jornalistas consagrados da mídia impressa nacional passam a ser contratados para atuar no rádio e na TV, como repórteres locais, jornalistas esportivos, bem como apresentadores de programas de entretenimento. 3) Institucionalização da formação em Jornalismo nos anos 1960, a partir da criação ou expansão de cursos superiores, que contribuíram para a consagração e produção da doxa do campo, isto é, do conhecimento comum aos integrantes do campo jornalístico.

Bolin argumenta que cada uma dessas mudanças vai contribuir para o aumento do número de jornalistas na televisão sueca, ocupando cargos relacionados ou não com a profissão. Mais do que o aumento desses profissionais em outras áreas de atuação, o cenário sueco, em termos de demografia, número de empreendimentos midiáticos e de cursos de jornalismo, permite que o autor possa descrever um campo jornalístico relativamente uniforme, no qual 
a maior parte de seus integrantes compartilha os mesmos conhecimentos. A partir dessas observações, o autor defende que os constantes atravessamentos entre jornalismo e entretenimento, por exemplo, quando um jornalista ocupa a função de apresentador de reality show ou quando um programa humorístico imita o estilo jornalístico, não demonstram necessariamente que o entretenimento é privilegiado em detrimento da informação séria, mas, pelo contrário, demonstram que o campo jornalístico consegue impor sua lógica, seus métodos (principalmente a entrevista) e seu texto para outros subcampos de produção cultural.

Para utilizarmos a análise de Bolin como uma proposta que pode contribuir para a reflexão sobre o fenômeno fake news, precisamos fazer algumas observações e ressalvas. Em primeiro lugar, não ignoramos a especificidade da análise do autor, que se refere ao cenário midiático televisual da Suécia. No entanto, das três mudanças ressaltadas nesse trabalho como "caminhos" para a autonomia jornalística, pelo menos duas delas podem ser observadas mais ou menos globalmente, a saber, a introdução da entrevista com o principal método e a institucionalização do treinamento jornalístico.

Sobre a introdução e legitimação da entrevista, o trabalho de Schudson (1994) que se propõe a traçar um panorama histórico dessa técnica no jornalismo norte-americano, já reafirmava sua importância para o campo:

A entrevista é o ato fundamental do jornalismo contemporâneo. Repórteres dependem esmagadoramente de entrevistas; De acordo com um estudo de repórteres de Washington na década de 1980, os jornalistas dependem tanto de entrevistas que não usam nenhum documento em quase três quartos das histórias que escrevem (Schudson, 1994, p. 565). ${ }^{11}$

No Brasil, a entrevista também ocupa lugar de destaque na prática jornalística, conforme os estudos de Adghirni (2002), Sant'Anna (2007) sobre as fontes jornalísticas e de Albuquerque (2013) sobre as entrevistas de candidatos à presidência no Jornal Nacional. Observando o local de onde surgem os grandes escândalos políticos nacionais, Adghirni constatou, com base na etnografia, que os jornalistas buscavam por informações inéditas ou exclusivas batendo

11 No original: "The interview is the fundamental act of contemporary journalism. Reporters rely overwhelmingly on interviews; according to a study of Washington reporters in the 1980s, journalists depend so heavily on interviews that they use no documents at all in nearly three-quarters of the stories they write" (Schudson, 1994, p. 565). 
"às portas mais altas do poder". Segundo ela, "a cobertura política do Congresso Nacional em Brasília se resume a atos de palavras" (Adghirni, 2002, p. 456). Já Albuquerque (2013, p. 18) afirmou que os apresentadores Jornal Nacional usam de forma agressiva essa prática para reivindicar para si um status político: o de representantes por excelência do interesse popular.

As entrevistas também fazem parte da história do jornalismo investigativo nacional. Segundo Waisbord (2000) e Fortes (2012), uma das investigações mais celebradas do jornalismo brasileiro foi aquela que culminou com o impeachment do Presidente Fernando Collor de Mello, em 1992. De acordo com o quê o primeiro autor relata, o jornal Folha de S. Paulo e a revista IstoÉ lideraram as primeiras denúncias de corrupção durante a candidatura do presidente de 1989, mas não tiveram muita repercussão devido ao posicionamento político de IstoÉ (que havia apoiado o oponente de Collor, Orestes Quércia, durante as eleições) e ao fato de que as denúncias não implicavam uma ação direta de Fernando Collor. A repercussão teria mudado drasticamente após uma entrevista com o irmão do presidente, Pedro Collor, publicada na revista Veja.

Quanto a institucionalização do treinamento ou formação em jornalismo, os primeiros cursos de jornalismo apareceram no início dos anos 1900 nos Estados Unidos. Na Europa, esse processo esperou pelo fim da Segunda Guerra Mundial. Conforme Bolin (2014) aponta, muitos países nórdicos tiveram seus primeiros cursos superiores de jornalismo fundados entre 1950 e 1960. No Reino Unido e em Portugal, a formação acadêmica em jornalismo começou a ser oferecida, respectivamente, em 1970 e 1979.

NoBrasil, o Decreto de 1943 adicionou a criação dos cursos dejornalismo no ensino superior às regulamentações da profissão, mas foi em 1947 que começou a funcionar o primeiro curso superior da área na Fundação Casper Líbero, em São Paulo. Durante a década de 50, ainda não havia "um posicionamento claro no interior do campo jornalístico a respeito do que deveria prevalecer como critério em termos de formação profissional: a experiência e o autodidatismo ou a formação universitária específica" (Roxo, 2016, p. 109). No entanto, com o Decreto-Lei № 972, de 17 de outubro de 1969, estabeleceu-se a obrigatoriedade do diploma de curso superior de jornalismo para o exercício da profissão, o que, por sua vez, teve forte papel de valorização dos cursos de jornalismo no país ${ }^{12}$. Podemos afirmar que, no caso brasileiro, o processo de regulamentação legal está na base do enfoque tecnicista que predominou na formação profissional do jornalismo e na própria definição de jornalista profissional, isto é, aqueles

12 O fim da exigência do diploma de jornalista para o exercício profissional foi determinado em 17 de junho de 2009 pelo Supremo Tribunal Federal. Para uma análise do processo, confira Lopes (2013). 
que pudessem comprovar o exercício da profissão antes de 21 de outubro de 1969 e para os que se formaram ou se formariam nos de Comunicação Social.

Estes dados são relevantes, pois, no estudo dos campos (Bourdieu, 1996), um aspecto importante para aquisição de autonomia diz respeito à construção de instituições que possam consagrar as crenças pelas quais o campo pode se reproduzir. De forma que o fortalecimento das instituições de formação a partir do fim da década de 1940 e o estabelecimento da obrigatoriedade do diploma em 1969 são indícios importantes do estabelecimento de uma doxa do campo no Brasil.

Dos fatores analisados por Bolin, o mais difícil de apropriar para a nossa reflexão diz respeito às mudanças nas políticas de recrutamento de jornalistas, uma vez que requerem um estudo amplo sobre os setores em que os jornalistas brasileiros estariam empregados. O Perfil do Jornalista Brasileiro (Mick e Lima, 2013, p. 61) nos fornece alguns indícios sobre esse aspecto ao tratar do trabalho de jornalistas fora da mídia, entretanto, devido a sua data, o estudo não nos fornece dados precisos para pensar, por exemplo, o recrutamento de jornalistas como redatores em sites de redes sociais. Ainda assim é surpreendente o fato de que, em 2012, 40,3\% dos jornalistas brasileiros trabalhava fora da mídia, "como assessores de imprensa ou comunicação ou em inúmeras outras funções mobilizando conhecimento jornalístico", e 74,5\% desses profissionais tinham tudo ou a maior parte da sua produção veiculada na internet.

Com estes casos e exemplos, queremos pontuar a pertinência de se pensar, em maior ou menor medida de acordo com cada caso, em um crescimento da autonomia do campo jornalístico em relação a outros subcampos de produção cultural. E, para trazer as implicações dessa análise para um estudo de fake news, precisamos pensar a relação do jornalismo, não só com a televisão, mas com os sites de redes sociais. Assim, defendemos que as redes sociais e sua crescente importância no acesso aos conteúdos noticiosos (54\% dos usuários de 36 países afirmaram utilizar as redes sociais como fonte de informação, segundo a Digital News Report 2017), não representam mais uma forma de contaminação do jornalismo, atendendo à nova lógica econômica de disputa pelo clique, ainda que, de fato, a internet e os sites de redes sociais não possam ser ignorados na análise dos constrangimentos econômicos que as empresas midiáticas enfrentam. Não negamos a dependência do jornalismo em relação ao campo econômico, mas, na disputa com outros subcampos de produção cultural, também acreditamos que o jornalismo tem conseguido impor a sua lógica, penetrando em sites de redes sociais, produzindo e divulgando conteúdo nesses espaços, conteúdos que são satirizados e apropriados em produtos distintos 
de notícias propriamente ditas. Desta forma, percebemos as fake news como produto da era do hiperjornalismo, isto é, como mais uma subforma jornalística. Autoridade jornalística e pacto de credibilidade

Até aqui tentamos explicitar nossa hipótese de que o fenômeno fake news está associado com o crescimento da autonomia do campo jornalístico em relação a outros subcampos de produção cultural. Não obstante, para amarrar esta hipótese, é ainda necessário nos determos em um aspecto: vimos que é possível defender a influência cultural do campo jornalístico por meio de suas regras específicas - principalmente representadas pela técnica da entrevista e da doxa adquirida na formação superior - em outros campos de produção cultural onde há recrutamento de jornalistas. No entanto, como defender lógica semelhante em uma subforma jornalística, como defendemos ser as fake news, que não é produzida por jornalistas (ALLCOTT e GENTZKOW, 2017)? Acreditamos que é possível lançar luzes sobre essa questão a partir dos estudos sobre autoridade jornalística e credibilidade.

A autoridade jornalística se tornou tópico de crescente discussão desde o início das transformações ocasionadas pela era digital e sua abundância de dados e informações, brevemente ilustrada na citação abaixo:

O New York Times reporta as notícias do dia. Junta-se a ele nesse esforço, a cacofonia do Twitter, a microssegmentação de um blog de bairro, listas-artigos do Buzzfeed, um infindável fluxo de comentários na televisão a cabo, o vasto reservatório de documentos secretos abrigados pelo WikiLeaks e uma multiplicidade de outros sites que também nos contam as notícias do dia. Neste ambiente midiático, o público enfrenta uma série desconcertante de notícias que afirmam representar ou explicar o mundo ${ }^{13}$ (Carlson, 2017, p. 2).

A nova facilidade de acesso à indústria noticiosa e a multiplicidade de mídias disponíveis a qualquer momento para os usuários, levou empresários e acadêmicos a se preocuparem com a capacidade das mídias tradicionais em manter a sua autoridade. No entanto, ainda que seja um tópico frequente nas discussões sobre os desafios atuais do jornalismo, a autoridade jornalística permanece como um conceito de definição frágil (Carlson, 2017). O ponto inicial

13 No original: "The New York Times delivers the news of the day. It is joined in this endeavor by cacophony of Twitter, the microtargeting of a neighborhood blog, Buzzfeed listicles, an endless stream of commentary on cable television, the vast reservoir of formally secret documents housed by WikiLeaks, and a multitude of other sites that also tell us the news of the day. In this media environment, audiences confront a bewildering array of news stories claiming to represent or explain the world"(Carlson, 2017, p.2). 
para tratar da questão é o trabalho de Zelizer (1992) sobre como as narrativas dos jornalistas relativas ao assassinato de John F. Kennedy também serviu para que eles se afirmassem como porta-vozes autorizados do assunto.

Conforme mencionamos na introdução deste artigo, a autora define autoridade jornalística como a "capacidade dos jornalistas de se afirmarem como porta-vozes legitimados e confiáveis dos eventos da 'vida real"' (Zelizer, 1992, p. 11). Para chegar a essa conceituação, Zelizer analisa o status do jornalismo como profissão e questiona se as comunidades de jornalistas são dotadas de um corpo básico de conhecimento codificado. O trabalho da autora é feliz em pontuar como o jornalismo parece escapar das "formas institucionais do profissionalismo" (1992, p. 8), portanto, argumenta que as profissões podem não ser o contexto ideal para se analisar a coletividade jornalística e que podem oferecer uma visão restritiva relativa à autoridade. A partir dessas observações, 0 que a autora enfatiza é o caráter de disputa que perpassa a autoridade jornalística.

Assim, ela nunca aparece como um efeito sobre o público, mas como algo que não é dado por garantido e é o produto de um esforço contínuo. No entanto, quando se fala, atualmente, das ameaças à autoridade jornalística diante da abundância da era digital, o que parece estar em questão é ainda uma autoridade com função de crença. Nossa intenção, mais alinhada com a definição de Zelizer, é tratar a questão a partir dos códigos de conhecimento coletivo que estão na base da construção da notícia.

Seguindo a trilha da autora, Carlson (2017) também apresenta uma nova definição de autoridade:

[...] como o direito de ser ouvido dentro de um contexto vinculado a relação assimétrica por meio da enunciação de discurso que inclui controle sobre um conhecimento particular e que está sujeito a contestação e mudança em virtude dos seus modos de legitimidade ${ }^{14}$ (Carlson, 2017, p. 12).

Para chegar a essa formulação, o autor parte de cinco premissas em torno da compreensão dessa noção: 1 . Autoridade como uma forma de autoridade comunicativa que garante a alguém o direito de falar e ser ouvido; 2 . Autoridade como uma relação assimétrica entre aqueles que a possuem e os que a

14 No original: "[...] being an authority as the right to be listened to ocurring within a context-bound asymmmetrical relationship through the performance of discourse that includes control over particular knowledge and that is subject to contestation and change regarding its modes of legitimacy" (Carlson, 2017, p. 12). 
reconhecem; 3. Autoridade como uma performance discursiva (enunciação); 4. Autoridade como o controle institucional sobre determinado conhecimento; e 5. Autoridade como algo sempre aberto para contestação.

Neste trabalho, gostaríamos de sublinhar principalmente a terceira premissa. Para que a autoridade seja vista como uma performance discursiva é preciso destacar dois aspectos: uma forma específica de uso da linguagem que tem por objetivo criar uma identidade e uma relação com os outros. Uma vez que os jornalistas não interagem diretamente com sua audiência, o peso da performance discursiva do jornalismo reside no texto noticioso. Dessa forma, a particularidade do texto noticioso - suas convenções formais, seu estilo visual e outros - está intimamente conectado com a afirmação da legitimidade do jornalismo. Dito isto, podemos ainda afirmar que a legitimidade do jornalismo não está amparada na suposta tentativa de mimetizar ou recitar fatos; é necessário compreender o texto jornalístico como uma forma narrativa que segue determinados padrões e convenções (cf. Resende, 2011). Segundo Carlson, o texto jornalístico fornece um código social compartilhado entre os jornalistas e seu público: "Os textos jornalísticos, então, não devem primariamente ser entendidos como tentativas de descrever mimeticamente eventos, mas como interpretações estratégicas deles, que oferecem aos jornalistas a possibilidade de afirmar a autoridade moral e, como resultado, obter poder"15 (Broersma citado por Carlson, 2017, p. 16).

Em capítulo dedicado ao estudo da informação e do boato, Sodré e Paiva (2011, p. 22) abordam a questão por outro viés. Partindo do questionamento da verdade no jornalismo, os autores argumentam que o regime de veridicção que legitima o jornalismo é lastreado pelo "compromisso histórico para com a ética do liberalismo", a partir da qual se impõe a narrativa de que o jornalismo serve aos cidadãos, garantindo sua liberdade de expressão. Para os autores, pensar nesses termos é importante porque demonstra que o jornalismo não está relacionado com uma demonstração lógico-filosófica da verdade, o que está em jogo é um pacto de credibilidade que institui suas próprias regras.

A ideologia do campo profissional procura sempre fazer passar a ideia de que a verdade do jornalismo pertence ao enunciado, ao invés da enunciação. A realidade, porém, é que, no pacto implícito entre o jornal e seu leitor, figura a cláusula de que o discurso do jornalista deva ser crível para que o público lhe outorgue o reconhecimento

15 No original: "Journalistic texts then should not primarily be understood as attempts to mimetically describe events, but as strategic interpretations of them, that offer journalists the possibility of asserting moral authority and, as a result, obtain power" (Broersma citado por Carlson, 2017, p. 16). 
da verdade. Essa credibilidade não nasce simplesmente de uma lógica do enunciado, e sim de uma hegemonia da enunciação, o que pressupõe uma luta ou um embate dos enunciados, de acordo com a variedade dos atores no acontecimento (Sodré e Paiva, 2011, p. 24)

Ainda que esse estudo tenha sido escrito em 2011, os autores já pontuam que a análise dos boatos (e do crescimento na circulação deles proporcionado pelas novas tecnologias) não deve estar focado no conteúdo lógico ou no enunciado, mas numa "economia de atenção" que se altera quando a imprensa se agiganta tornando-se "mídia", isto é, "uma forma de vida articulada com mercado e tecnologias da informação" (Sodré e Paiva, 2011, p. 22), num contexto de esvaziamento do liberalismo clássico que está na base do pacto de credibilidade jornalístico.

Diante desta expansão: "Tornamo-nos todos repórteres, redatores e fotógrafos" (Sodré e Paiva, 2011, p. 28). Este aspecto também é pontuado por Deuze e Witschge $(2017$, p. 5), ao observar que, até recentemente, a participação dos jornalistas na construção discursiva do jornalismo estava sujeita a estar empregado em uma redação, forma dominante de organização do trabalho jornalístico durante todo o século XX. Agora, no entanto, é preciso pensar a profissão como uma prática de redes que envolve uma variedade de atores (incluindo até "robôs produzindo notícias").

Podemos observar esse movimento nas novas subformas jornalísticas que têm aparecido no Brasil. Para ilustrar, poderíamos citar o programa de TV Greg News, produzido pela HBO Brasil, que traz a interpretação do humorista Gregório Duvivier para as principais notícias do Brasil. Apesar de estar definido como gênero comédia, o cenário, o figurino, a postura do apresentador e o próprio uso de notícias e dados factuais emulam mecanismos da enunciação jornalística. Outro exemplo semelhante é do podcast Mamilos (programa de rádio veiculado na internet) que se autodefine como "jornalismo de peito aberto", mesmo sem ser produzido por jornalistas (de formação). Juliana Wallauer, formada em Administração, e Cris Bartis, publicitária, são as criadoras e apresentadoras do programa, cuja proposta é discutir os temas mais comentados nas redes sociais com empatia ${ }^{16}$

Neste ponto, os caminhos que viemos traçando até aqui se encontram. De um lado, compreendemos o jornalismo como um subcampo de produção cultural que vem conquistando autonomia sobre outros subcampos; de outro, o jornalismo é visto como uma profissão pouco formalizada, que se fundamenta

16 Ver Araújo (2016). 
em códigos sociais de conhecimento e em um pacto de credibilidade para afirmar a legitimidade da sua interpretação dos fatos. Em ambos, se destaca uma visão ampla do jornalismo como realização cultural, que vai além do texto noticioso e das características organizacionais de produção, englobando também o reconhecimento da audiência (mecanismos receptivo-cognitivos do público).

Segundo essa linha de raciocínio, entendemos as notícias falsas menos como um ataque externo ao jornalismo e à sua credibilidade, e mais como inserção de novos agentes no cenário complexo da prática jornalística, que envolve tecnologias, fontes de informação, anunciantes, empresas midiáticas, audiência, formuladores de políticas públicas e críticos.

Se pensarmos na maleabilidade da autoridade jornalística e se atualizarmos os três pilares da análise de Bolin (2014) - isto é, o estabelecimento de técnicas jornalísticas, o crescente acesso de jornalistas a outras áreas de atuação e a institucionalização do ensino de jornalismo - é fácil compreender a complexificação do cenário atual. As notícias falsas divulgadas em redes sociais emulam o texto jornalístico para, com isso, também se apropriar do código social que legitima o trabalho jornalístico. No entanto, essa estratégia só tem condições de emergir (e ser mais ou menos bem-sucedida) porque há um enfraquecimento do pacto de credibilidade e, em consequência, da própria definição de notícia e de empresa jornalística. Enquanto Bolin (2014) aponta que a maior parte dos jornalistas suecos atuantes no período de sua análise se formaram na mesma universidade, atualmente o acesso a cursos de jornalismo se expandiu consideravelmente, bem como aumentou o número de associações e organizações de classe. Isso se reflete nas próprias questões que os pesquisadores se colocam:

O que é jornalismo na visão das nossas faculdades? Sejamos um pouco menos superficiais e perguntemos algo além disso: será que as escolas de jornalismo têm uma visão clara e compartilhada do que vem a ser a imprensa? A verdade - desconcertante - é que não há entre nós um conceito claro dessa profissão, e essa falta de clareza não se resume às escolas. Os sindicatos de jornalistas espalhados pelos estados, assim como a Federação Nacional dos Jornalistas (Fenaj), partilham de uma visão nebulosa, indefinida, vaga, segundo a qual os repórteres de uma redação independente e os assessores de imprensa de um partido político ou de uma agremiação futebolística exercem a mesma profissão (Bucci, 2012, p. 27).

Em um cenário jornalístico menos ou pouco coeso, o apelo por um jornalismo participativo também aumenta, devido a redução da assimetria 
entre o jornalismo e sua audiência em relação ao acesso aos fatos e fontes de informação. Como defende Karlsson (2011), a velocidade da internet permite que a audiência possa ver em tempo real os processos de aquisição e apuração de informações. Utilizando os conceitos de backstage (bastidor) e frontstage (palco), o autor pontua a mudança de visibilidade dos processos de trabalho entre o jornalismo impresso e o online, este último teria dado visibilidade e transparência para os processos de coleta de informação.

O frontstage da era analógica caracterizou-se pela disseminação de notícias acabadas, com apenas alguns agentes criando einfluenciando as notícias e o modo de transmissão da comunicação. Na era digital, o frontstage inclui o fluxo contínuo de rascunhos, muitos participantes em potencial no processo de criação de notícias, uma redução no modo de transmissão de comunicação e um aumento nas formas alternativas de comunicação. ${ }^{17}$ (Karlsson, 2011, p. 291).

Assim, mudanças na participação da audiência, na visibilidade dos processos jornalísticos e no acesso aos meios de comunicação e às fontes contribuem para o enfraquecimento da autoridade jornalística, seja, como dissemos, pela redução da assimetria entre os jornalistas e a audiência, seja pela dificuldade de conceber o jornalismo como domínio de um conhecimento específico. O jornalismo, como profissão, sempre se diferenciou da medicina ou da ciência com seus discursos esotéricos; o discurso jornalístico não precisa ser traduzido, pelo contrário, tem como característica a acessibilidade e o grande alcance. De forma que a expertise que os jornalistas alegam é a de ter acesso e lidar com experts, documentos e outras fontes de informação. Quando essa "expertise" se torna mais acessível para amadores ou, como se tem chamado, "jornalistas cidadãos" (Bock, 2011), a autoridade jornalística também se torna mais aberta a contestação.

Retornando à indagação que fazíamos no início desse artigo - sobre qual seria, então, a(s) consequência(s) da utilização de métodos e linguagens jornalísticas em outros gêneros de produção cultural desvinculados do compromisso com a verdade e com objetivos distintos do jornalismo - a reflexão que conduzimos até agora nos leva a defender que as fake news, bem

17 No original: "The frontstage area in the analogue era was characterized by disseminating finished news, with only a few participants creating and influencing the news and the transmission mode of communication. In the digital era the frontstage area includes the continuous flow of drafts, many potential participants in the news creation process, a reduction in the transmission mode of communication, and a rise in alternative forms of communication" (Karlsson, 2011, p. 291). 
como outras formas de produtos híbridos característico do que chamamos de era do "hiperjornalismo", ao mesmo tempo em que representam o aumento da autonomia do campo jornalístico sobre outros subcampos de produção cultural, também contribuem para a fragilização dos códigos sociais de conhecimento relativos à comunidade jornalística. Isto acontece pela apropriação do texto noticioso, discurso de fundamental importância para a legitimação da profissão, em um cenário de pouca coesão institucional na profissão.

Dessa forma, acreditamos que as propostas para o enfrentamento à propagação de notícias falsas em redes sociais deveriam também refletir sobre as dificuldades de afirmação da autoridade jornalística enfrentadas atualmente.

\section{Conclusão}

Com este trabalho, que foge à pretensão de se apresentar como tese atemporal e válida para o jornalismo em geral, intentamos principalmente abrir novas possibilidades de análise seja para as notícias falsas, seja para produtos híbridos de jornalismo (e entretenimento, literatura, política etc.). Assim, apresentamos uma provocadora análise de viés bourdieusiano realizada na Suécia e procuramos estudar, no campo jornalístico brasileiro, os mesmos aspectos estudados por Bolin (2014). Isto é, se é possível observar: 1) a emergência da entrevista como o principal método jornalístico; 2) mudanças nas políticas de recrutamento de jornalistas em outros campos de produção cultural; e 3) institucionalização da formação em Jornalismo. Ainda que cada um desses pontos demande uma análise mais detida, o que podemos reunir na organização desse texto nos parece indicar que, no Brasil, também há a formação de uma doxa jornalística, bem como a circulação de jornalistas por outros campos (Pontes e Mick, 2018).

A forma como se tem tentado definir o fenômeno fake news e a busca de soluções para ele, que foca em métodos para separar o que verdadeiro do falso, demonstram uma visão limitada da própria concepção de jornalismo, que não reflete a complexidade do jornalismo enquanto subcampo de produção cultural com capacidade de impor sua lógica sobre outros subcampos.

Dito isto, defendemos que não é em torno das oposições entre verdade e mentira, entre investigação jornalística ou falta de investigação, que poderemos avançar na discussão das fake news. Sugerimos que a discussão da veracidade não pode ser separada da discussão da autoridade e que, no âmago das campanhas em prol da verdade, o que se tenta recuperar não é algo intrínseco ao conteúdo da notícia, não é algo que diz respeito ao dito.

As notícias falsas, ao emular o texto jornalístico, reencenam também a performance discursiva que garante legitimidade ao jornalismo. Em sites com 
diagramações e endereços semelhantes (nos Estados Unidos: NationalReport. net, USAToday.com.co, denverguardian.com, WashingtonPost.com.co; no Brasil: correiodopoder.com, diariodobrasil.org, folhadopovo.com, entre outros) ao de portais de notícias, utilizando também imagens, ainda que falsas, para ancorar o que é dito, as fake news buscam acionar o mesmo código social compartilhado entre os jornalistas e seus leitores, código este responsável em grande parte pela autoridade jornalística. O que está em questão é, notadamente, o reposicionamento dos jornalistas na posição de observadores legítimos e confiáveis do "mundo real".

\section{REFERÊNCIAS}

ADGHIRNI, Z. L. Rotinas produtivas do jornalismo em Brasília. In: MOUILLARD, M; PORTO, S. D. O jornal: da forma ao sentido. Brasília: Editora Universitária de Brasília, 2002.

ALLCOTT, Hunt; GENTZKOW, Matthew. "Social Media and Fake News in the 2016 Election". Journal of Economic Perspectives, v. 31, n. 2, Spring/2017. p. 211236. Disponível em: http://pubs.aeaweb.org/doi/pdfplus/10.1257/jep.31.2.211. Acesso em: 27. abr. 2018.

ARAÚJO, P. Cris Bartis e Ju Wallauer: as minas da polêmica. Vice. 19. set. 2016. Disponível em: https://www.vice.com/pt_br/article/wdbjyb/as-minas-da-polemica-avonfemme. Acesso em: 27. abr. 2018.

BOCK, M. Citizen video journalists and authority in narrative: reviving the role of the witness.Journalism.v.13,n.5.,2011.p.639-653.DOI:10.1177/1464884911421703.

BOLIN, Göran. Television Journalism, Politics, and Entertainment: power and autonomy in the field of television journalism. Television \& New Media. v. 15, n. 4, 2014. p. 336-349. Disponível em: https://doi.org/10.1177/1527476414525671. Acesso em: 27. abr. 2018.

BOURDIEU, P. Sobre a televisão. Rio de Janeiro: Jorge Zahar, 1997.

BOYD, Danah. Did Media Literacy Backfire? Data \& Society: Points. 5. jan. 2017. Disponível em: https://points.datasociety.net/did-media-literacy-backfire7418c084d88d. Acesso em: 27. abr. 2018.

BRANTS, K. "Who's Afraid of Infotainment?" European Journal of Communication. v. 13, n. 3, 1998. p. 315-335. Disponível em: https://doi.org/10.1177/02673231980 13003002. Acesso em: 27. abr. 2018.

BUCCl, E. Uma profissão, um conceito. Revista de Jornalismo da ESPM, outubro, novembro e dezembro, 2012. p. 26-30. 
CAPLAN, Robyn. How do you deal with a problem like "fake news"?. Data \& Society: Points, 5. jan. 2017. Disponível em: https://points.datasociety.net/how-do-youdeal-with-a-problem-like-fake-news-80f9987988a9. Acesso em: 27. abr. 2018.

CARLSON, M. Journalistic authority: legitimating news in the digital era. New York: Columbia University Press, 2017.

CHAMPAGNE, P. “The 'Double Dependency': The Journalistic Field between Politics and Markets." In: BENSON, R. e NEVEU, E. Bourdieu and the Journalistic Field, Cambridge, UK: Polity, (1995) 2005.

DEUZE, Mark; WITSCHGE, Tamara. Beyond journalism: Theorizing the transformation of journalism. Journalism, 7. fev. 2017. p. 165-181.

FLETCHER, R;NEWMAN, N.etal. Reuters Institute Digital News Report 2017.Disponível em: $\quad$ https://reutersinstitute.politics.ox.ac.uk/sites/default/files/Digital\%20 News\%20Report\%202017\%20web_0.pdf?utm_source=digitalnewsreport. org\&utm_medium=referral. Acesso em: 14 jul. 2017.

FORTES, L. Jornalismo Investigativo. São Paulo: Contexto, 2012.

GOMES, I.Tendências do telejornalismo brasileiro no início do século XXI: telejornalismo popular e infotainment. In: João Freire Filho; Gabriela Borges. (Org.). Estudos de Televisão: diálogos Brasil-Portugal. 1. ed. Porto Alegre: Sulina, 2011. p. 56-87.

KARLSSON, M. The immediacy of online news, the visibility of journalistic processes and a restructuring of journalistic authority. Journalism, v. 12, n. 3, 2011. p. 279295. DOI: $10.1177 / 1464884910388223$.

MOSSERI, A. Working to Stop Misinformation and False News. Facebook Newsroom. Disponível em: https://newsroom.fb.com/news/2017/04/working-to-stopmisinformation-and-false-news/. Acesso em: 15. jul. 2017.

PONTES, F.; MICK, J. Crise e mercado de trabalho: trajetórias profissionais de jornalistas no Brasil (2012-2017). jun./2018. In: Anais do XXVII Encontro Anual da Compós, Pontifícia Universidade Católica de Minas Gerais, Belo Horizonte - MG.

POST-TRUTH. English Oxford Living Dictionaries. Disponível em: https:// en.oxforddictionaries.com/word-of-the-year/word-of-the-year-2016. Acesso em: 12. jul. 2017.

RESENDE, F. Às desordens e aos sentidos: a narrativa como problema de pesquisa. In: SILVA, G. et al (org.). Jornalismo contemporâneo: figurações, impasses e perspectivas. Salvador: EDUFBA; Brasília: Compós, 2011.

ROXO, M. Jornalistas pra quê? Militância sindical e o drama da identidade profissional. Curitiba: Appris, 2016.

SANT'ANNA, F. Quem faz a notícia no parlamento brasileiro? Análise comparativa das 
rotinas dos newsmakers do Senado Federal. Biblioteca on-line de ciências da comunicação, 2007. Disponível em: http://www.bocc.ubi.pt/pag/santannafrancisco-quem-faz-a-noticia-parlamento.pdf. Acesso em: 6. mai. 2015.

SODRÉ, M. e PAIVA, R. Informação e boato na rede. In: SILVA, G. et al (org.). Jornalismo contemporâneo: figurações, impasses e perspectivas. Salvador: EDUFBA; Brasília: Compós, 2011.

WAISBORD, S. Watchdog journalism in South America: news, accountability, and democracy. New York: Columbia University Press, 2000.

ZELIZER, Barbie. Introduction: narrative, collective memory and journalistic authority. In: Covering the body: the Kennedy assassination, the media, and the shaping of collective memory. Chicago \& London: University of Chicago Press, 1992. p. 1-13. Traduzido para o português por MTGF de Albuquerque. Rev. técn. de A. de Albuquerque.

ZUCKERMAN, Ethan. Fakenews is a red herring. DeutscheWelle, 25.jan.2017. Disponível em: http://www.dw.com/en/fake-news-is-a-red-herring/a-37269377. Acesso em: 27. abr. 2018.

Recebido em: 01/05/2018

Aceito em: 14/06/2018

Dados dos autores:

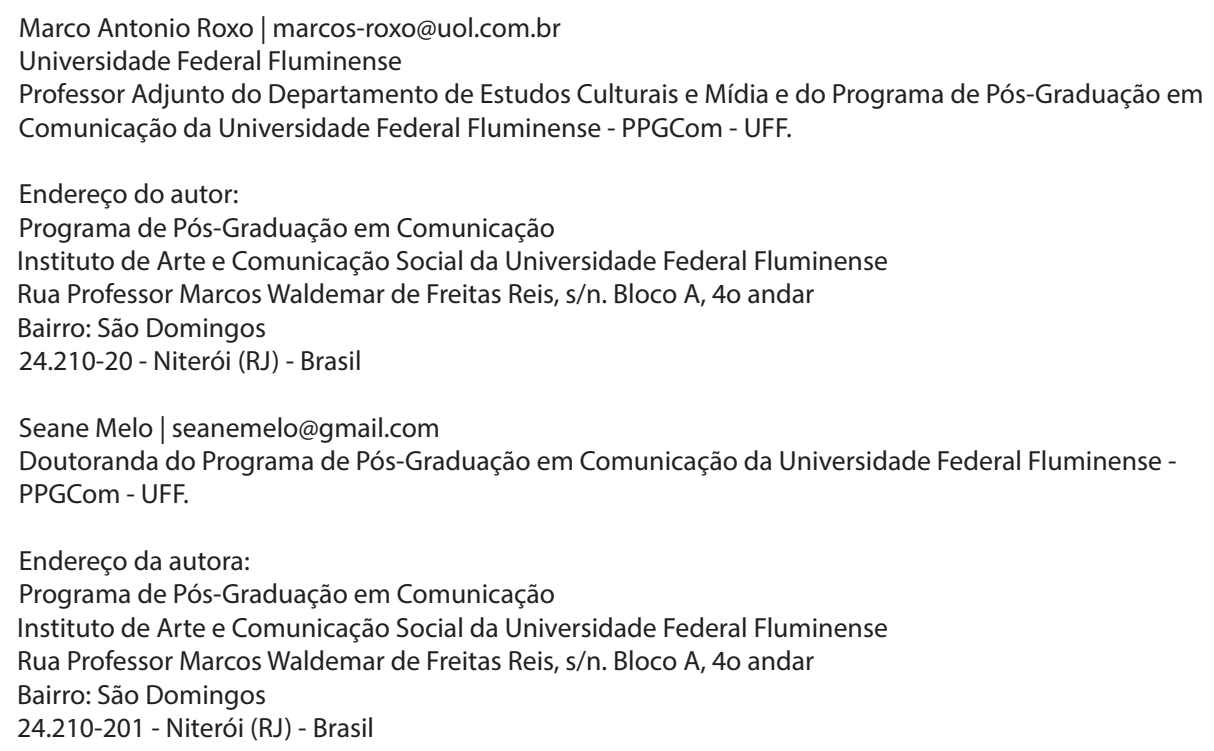

Contribuições dos autores: Ambos, autor e autora, fizeram contribuições substanciais para concepção, desenvolvimento, redação e revisão crítica do trabalho; e aprovação final da versão para publicação. 